\title{
Type I Diabetes and the Role of Inflammatory-Related Cellular Signaling
}

\author{
Lloyd Jesse ${ }^{1}$, Kelleher Andrew ${ }^{2}$, Choi Myung${ }^{1}$ and Keslacy Stefan ${ }^{1}$ \\ ${ }^{1}$ Syracuse University, Department of Exercise Science, Syracuse NY \\ ${ }^{2}$ Pennsylvania State College of Medicine Dept of Physiology H166, Hershey, PA \\ United States of America
}

\section{Introduction}

Type 1 (T1DM) proceeds from a complete absence of insulin due to an autoimmuneassociated degradation of the insulin-secreting pancreatic $\beta$-cell. An islet autoimmune response seems to be regulated by the T-helper lymphocyte and its cytokine products including IL-2, IFN- $\gamma$, and TNF- $\beta$, causing a cascade of inflammatory processes, known as insulitis and consequently gradual $\beta$-cell degradation (Rabinovitch and Suarez-Pinzon 2003). Therefore, T1DM etiology follows two stages. First, insulitis appears when various leukocytes attack the pancreas islets. Second, diabetes develops when most $\beta$-cells have been degraded, and there is no longer adequate insulin secretion to regulate blood glucose levels, leading to hyperglycemia (Mathis, Vence et al. 2001). Chronic hyperglycemia is believed to cause insulin resistance in T1DM (Patti, Maffettone et al. 1999). Thus, people can have concealed insulitis for years before it finally induces overt diabetes. Although most of diabetic patients suffer from T2DM, compelling evidence demonstrated that a proportion of people initially diagnosed with T2DM may in fact have a gradually progressing and less severe category of T1DM (Bell and Polonsky 2001). People affected by T1DM are constrained to insulin administration on a regular basis either through injections, pumps, or by inhalation. Outwardly, T1DM patients appear predominantly healthy; however failure to adhere to the appropriate treatment to effectively control blood glucose levels could lead to increased fatigue, neuropathies and long-term organ damages. The consequences of the autoimmunological destruction of pancreatic $\beta$-cells are clear, the causes are not, and the identification of the environmental factors that induce this destruction in genetically susceptible children, adolescents, and even adults still eludes us (Mathis, Vence et al. 2001).

\section{Inflammation}

In T1DM, it is suggested that inflammation contributes to the inhibition or stimulation of $\beta$ cell reformation and $\beta$-cell destruction, leading to peripheral insulin resistance (Eizirik, Colli et al. 2009). Inflammation is brought on by various cell mediators or cellular signals. Among them, cytokines, such as members of the interleukin family (IL-6, IL-1 $\beta$ ), tumor necrosis super family (TNF- $\alpha$ ), and the interferon family (INF- $\alpha, \beta$, and $\gamma$ ), play an essential role in initiating and perpetuating the inflammatory process. Most of the T1DM-associated cytokines are involved in inflammation induced cellular apoptosis through the activation of 
a specific transcription factor: nuclear factor kappa-light-chain-enhancer of activated B cells (NF-kB).

\subsection{Immunity and T1DM}

In order to better understand the etiology of T1DM, plethora of research has been done to link the systematic destruction of $\beta$ - cells and immunity. In all mammals there are two types of immune responses: adaptive and innate those mainly differ with regards to the types of receptors that recognize antigens. Innate responses are non-specific compare to adaptive which are fairly specialized based on the antigen. The key cellular players of innate immunity are dendritic cells, macrophages, mast cells and natural killer cells. They function through complex systems of T-cell surface receptors that recognize and destroy antigens produced from micro-organisms. Adaptive immunity is more specific, employing $\mathrm{T}$ and $\mathrm{B}$ cells that provide life-long immunity following the immunization process.

\subsubsection{The role of innate immunity in T1DM}

Activation of the receptors involved in innate immunity contributes to the development of autoimmune diseases including insulitis and T1DM. Pattern-recognition receptors (PRRs) are a class of receptors involved in the innate immune response and includes toll-like receptors (TLRs). It is possible that the binding of endogenous ligands to PRRs, specifically TLRs, may induce the inflammatory response that leads to $\beta$-cell destruction and T1DM. This theory is supported by animal models of autoimmune dysfunction; whereby TLRs contributed to an innate immune response to pancreatic $\beta$-cells and led to insulitis and T1DM (Zipris 2008). Specifically, TLR2 and TLR4 deficient mice were resistant to posttransplantation of islet cells induced T1DM and related inflammation (Goldberg, Parolini et al. 2007; Kim, Han et al. 2007). Although experiments such as these support a link between specific PRRs and T1DM development, other data suggest complex interactions between the immune system, genes, and other biochemical factors. For example, there was no difference in T1DM prevalence observed when TLR2 and TLR4 were genetically deleted from nonobese diabetic mice (NOD) (Wen, Ley et al. 2008). In that study, the nature of the animal's intestinal flora was thought to counter the effect of TLRs' absence. Other studies support that $\beta$-cell death can be caused by viral infections, most notably from enteroviruses, as viral antigens can elicit an acute inflammatory response. Enteroviruses infection occurred in half the subjects in a study assessing $\beta$-cells in patients with T1DM (Dotta, Censini et al. 2007). In addition, T1DM is characterized as an autoimmune disorder, as $\beta$-cells are also accessible to antigens-presenting cells: macrophages and dendritic cells. Therefore, macrophages are recruited to the pancreas of people suffering from T1DM and insulitis where they produce inflammatory cytokines such as IL- $1 \beta$ and TNF- $\alpha$, involved in $\beta$-cell death (Uno, Imagawa et al. 2007). It has been also suggested that patients with T1DM have alterations in innate immunity in the peripheral blood, specifically in dendritic cells, mononuclear and plasmacytoid. These data support links between $\beta$-cell death, inflammation and innate immune responses and provide evidence that the innate immunity is a target of choice for T1DM treatments.

\subsubsection{The role of adaptive immunity in T1DM}

The nature of the biochemical reactions that occur during and following an acute inflammatory response may be key to determining whether autoimmunity develops with 
the potential to destroy $\beta$-cells and progress to T1DM. Altered expression of chemokines, signaling molecules that direct immune cells during inflammation, has been observed in several autoimmune disorders including T1DM. Certain chemokines such as CCL3, CCL4, CXCL10, have been shown to be elevated in T1DM patients (Shimada, Morimoto et al. 2001; Nicoletti, Conget et al. 2002; Hanifi-Moghaddam, Kappler et al. 2006). CCL3 has also been negatively correlated with C-peptide which is involved in insulin action (Pfleger, Kaas et al. 2008). Due to the difficulty accessing the pancreatic tissues to observe inflammatory markers, new methods have been developed to measure the response of immune cells from the systemic circulation in patients with T1DM. Using genetic microarray analysis, a T1DM "signature" pattern of chemokine and cytokine expression was revealed (Wang, Jia et al. 2008). Animal models of T1DM have displayed macrophages islet infiltration during the initial stages of the disease, responsible for chemokines production, namely CXCL10 and CCL2 (Martin, Rankin et al. 2008). Indeed, high levels of CCL2 in human islets have been associated with poor treatment prognosis after islet transplantation (Piemonti, Leone et al. 2002). Other chemokines have also been implicated in the development of autoimmune diabetes including CCL3 and CCL5 both of which have been positively correlated with insulitis and islet destruction in a murine model (Abdi, Smith et al. 2002). When exposed to inflammatory mediators during insulitis, it has been shown that the $\beta$-cells themselves can produce cytokines and chemokines (Eizirik, Moore et al. 2008). The expression of chemokines by $\beta$-cells is at mainly regulated by NF- $\kappa B$, which also mediates $\beta$-cell death (Eldor, Yeffet et al. 2006). It is believed that dying $\beta$-cells may fuel the initial development of the autoimmune response which characterizes T1DM (Eizirik and Mandrup-Poulsen 2001; Cnop, Welsh et al. 2005). Proteins production resulting from an acute bout of islet inflammation, such as cytokines and chemokines, may facilitate the presentation of apoptosed $\beta$-cells to lymphocytes involved in the adaptive immune response (Filippi and von Herrath 2005). Another interesting mechanism by which $\beta$-cells fall victim to the adaptive immune system is through a stress response initiated by an accumulation of misfolded proteins in the $\beta$-cell endoplasmic reticulum (ER) (Cardozo, Ortis et al. 2005; Dogusan, Garcia et al. 2008). The presence of such proteins occurs as a result of inflammation in and around $\beta$-cells. Normally, the stress response to misfolded proteins restores balance to the ER by shuttling proteins out and preventing synthesis of new proteins into the ER. However, an error in this system can result in increased ER stress and $\beta$-cell apoptosis initiating the adaptive immune response (Cardozo, Ortis et al. 2005). Given the fact that insulin accounts for roughly half of the proteins produced by $\beta$-cells, therefore it is likely that the accumulation of misfolded insulin-related proteins could contribute to ER stress and the resulting response. As part of the dying $\beta$-cells, insulin could become a antigen recognized by effectors cells, thus explaining the autoimmune origin to $\beta$-cells apoptosis that occurs in T1DM. Ironically, the same inflammatory mediators involved in $\beta$-cell destruction may also contribute to $\beta$-cell proliferation and thus, the resolution of insulitis (Sarvetnick and Gu 1992; Sherry, Kushner et al. 2006). Although not yet observed in humans, $\beta$-cell proliferation has been seen in mice genetically modified to express high cytokine levels, and immunosuppression has also been shown to suppress $\beta$-cell generation (32).

\subsubsection{At the frontier of inflammation and apoptosis: NF- $\mathrm{KB}$ signalling in T1DM}

$\mathrm{NF}-\kappa \mathrm{B}$, known as the "master regulator" of the inflammatory process, is a multi-protein complex transcription factor that mediates more than 200 genes. There are several internal 
and external factors associated with T1DM that affect the activation of NF- $\kappa \mathrm{B}$, most notably: reactive oxygen species (ROS), TNF- $\alpha$, IL-1 $\beta$, nitric oxide (NO) and inducible nitric oxide synthase (iNOS). Proper regulation of NF- $\kappa B$ is crucial for a healthy immune response. Conversely, a disruption in the NF- $\kappa \mathrm{B}$ pathway often leads to the onset and/or progression of several types of cancers as well as viral infections, impaired immune function, and autoimmune disorders. It has been suggested that the ability to regulate specific cytokines, proteins or genes that activate the NF- $\mathrm{KB}$ cascade is crucial at slowing the progression of T1DM. For example, inflammation triggers NO production, an important transcription factor in iNOS gene expression, which then activates NF- $\kappa \mathrm{B}$ in peripheral blood mononuclear cells (Igoillo-Esteve, Gurzov et al.). A recent study demonstrated an upregulation of the expression of B-cell lymphoma-6 (Bcl-6), a sequence-specific repressor of transcription, in $\beta$-cells which decreased programmed cell death, iNOS expression, NO production, and NF- $\mathrm{B}$ activation (Igoillo-Esteve, Gurzov et al.). This reveals the essential role that NF- $\kappa B$ signaling can play in $\beta$-cell damage and/or destruction. This notion has been demonstrated using transgenic mouse models where genes associated with NF- $\mathrm{B}$ activation have been over expressed or knocked-down (Mathews, Suarez-Pinzon et al. 2005). ALR/Lt transgenic mice, which $\beta$-cells are engineered to resist apoptosis, showed resistance to stress induced by free radical damage. This resistance causes a failure in the production of pro-inflammatory cytokines (IL1- $\beta, \mathrm{TNF} \alpha$, and IFN $\gamma$ ) by inhibiting NF- $\mathrm{BB}$ activation. These outcomes coupled with decreased ROS accumulation leads to decreased $\beta$-cell death (Mathews, Suarez-Pinzon et al. 2005). More recently, the role of NF- $\kappa B$ has been associated with chromatin modifying enzymes, histone acetyltransferase, and histone deacetylase (HDAC). Positive effects associated with NF- $\kappa B$ expression on HDAC inhibition have been obtained for several inflammatory diseases (Keslacy, Tliba et al. 2007). HDAC inhibition lowered cytokine-mediated insulin resistance and increased iNOS levels, NO formation, and apoptosis. IL-1- $\beta$ induced a biphasic phosphorylation of inhibitor protein IкBa with the second peak in the phase being sensitive to HDAC (Larsen, Tonnesen et al. 2007). These studies clearly demonstrate the contribution of NF- $\kappa$ B cascade activation to T1DM.

\subsubsection{Transplantation of islet cells only promising because of inflammation?}

Transplanting islet cells is a technique that has emerged in the past few years for treating individuals with T1DM. The current therapy is life-long exogenous insulin supplementation (Gillespie 2006). Although exogenous insulin administration is generally effective, it does not allow for physiological control over blood glucose levels resulting in micro and macrovascular consequences. Even when delivered in steady-controlled doses via insulin pumps, the results are not as effective as islet transplantation. Islet cells transplantation appears as a treatment of choice for T1DM, however, recent five-year follow-up studies showed that most of the islet cells that were transplanted were destroyed due to inflammation activation (Nanji and Shapiro 2004; Balamurugan, Bottino et al. 2006). Islet cells have a unique transplantation progression, as the rejection of the graft does not seem to follow the same rejection processes observed during other whole organ transplants. It has been shown that instead of the tissue itself, rejection was related to islet quality and vascularization, innate immunity, and coagulation (Swift, Clayton et al. 1998; Bach, Bendelac et al. 2004). Non-specific inflammation at the site of transplantation can occur in islet $\beta$-cells. In transplant models, stress as a result of the isolation procedure induced secretion of proinflammatory cytokines contributing to early islet graft loss after transplantation. This 
could represent one of the contributing factors for the destruction of the islet graft over time (Barbe-Tuana, Klein et al. 2006). A potential method of ensuring proper graft transplantation acceptance could result from CD40. It is a member of the TNF receptor family that binds to CD40L and is expressed in pancreatic $\beta$-cells. CD40 upregulates intracellular adhesion molecule-1 associated with inflammation at both transcriptional and translational levels. Inhibition of CD40 expression decreased in a dose dependent manner NF-kB-associated proinflammatory cytokines and protected human pancreatic duct cells (Vosters, Beuneu et al. 2008).

\section{Insulin signaling: between treatment and etiology in T1DM}

Inflammatory mediators from adaptive immune response are likely involved in the resolution or maintenance of insulitis that ultimately leading to T1DM. However, despite exhibiting the level of hyperglycemia recognized in T1DM diagnosis, some patients demonstrate higher insulin levels than would be expected with severe $\beta$-cell destruction. It has been hypothesized that the inflammatory mediators involved in $\beta$-cell dysfunction may also contribute to peripheral insulin resistance, thus resulting in the observed hyperglycemia (Strandell, Eizirik et al. 1990). Therefore, it is possible that the metabolic abnormalities of T1DM are the result of the associated development of progressive insulitis and insulin resistance. Though the consequences of progressive insulitis and T1DM can be dire, not all individuals who develop insulitis proceed to a full-fledged T1DM diagnosis (Eizirik, Sandler et al. 1993).

\subsection{Underlying insulin signaling mechanisms on glucose transport}

Insulin is the primary regulator of blood glucose level and a key signaling to better understand the pathology of T1DM. Biologically active human insulin consists of two polypeptide chains, the A chain ( 21 amino acids) and B chain (30 amino acids), joined by two interchain disulfide-linked bridges at A-Cys7/B-Cys7 and A-Cys20/B-Cys19 with an interconnnected disulfide bridge between A-Cys20/ A-Cys11 (Steiner, 1985). Insulin triggers a wide variety of metabolic and mitogenic events by activating a series of intracellular signaling cascades (Zierath 2002; Wright, Ryals et al. 2004). The effect of insulin is mediated through binding to the heterotetrameric insulin receptor (IR) and activating intrinsic tyrosine kinase activity via autophosphorylation (Farese 2001). Phosphorylated tyrosine residues on the activated IR provide docking sites for insulin receptor substrates (IRSs) that contain SH2 (Src-homology 2) domains. IRS-1 and IRS-2 are widely expressed in tissues metabolically involved in glucose and lipid homeostasis (Sun, Rothenberg et al. 1991; Sun, Wang et al. 1995), and are therefore found in skeletal muscle, liver, fat, and pancreatic islets. While IRS-1 appears to play a more important role in skeletal muscle metabolism than IRS-2, it is thought that IRS-2 has a greater function in liver and islet $\beta$ cells (Sun, Wang et al. 1995). Once phosphorylated by IR, IRS-1 activates a cellular cascade and binds to p85 regulatory subunit of phosphatidylinositol (PI) 3-kinase, which in turn activates the p110 catalytic subunit (Czech and Corvera 1999). To date, five isoforms of regulatory subunits of PI 3kinase have been identified in skeletal muscle, including two classical isoforms (p85a and $\mathrm{p} 85 \beta$ ) and three other isoforms (p55a, p55 $\gamma$, and p50a) (Shepherd, Nave et al. 1997). Activated PI 3-kinase specifically phosphorylates the D3 position of the cellular phosphoinositides to produce phosphatidylinositol 3-monophosphate (PI-3-P), PI-3,4bisphosphate (PIP2), and PI-3,4,5-triphosphate (PIP3) (Alessi, Deak et al. 1997; Alessi 2001). 
These unique phospholipids serve as docking sites for cytoplasmic proteins with pleckstrin homology (PH) domains, including the serine/threonine kinases Akt/PKB and phosphoinositide-dependent kinase-1 (PDK1). The PH domain of Akt/PKB is displaced by 3-phosphoinositides and exposes regulatory phosphorylation sites in the catalytic/regulatory domain of the enzyme. Moreover, by recruiting both Akt and PDK1 to common membrane domains, the two enzymes come into closer proximity, promoting the phosphorylation of the Thr308 residue by PDK1. Ser473 phosphorylation is promoted by 3phosphoinositides, through a second mechanism not involving the recruitment of Akt to the plasma membrane, which is required for Thr308 phosphorylation. The enzyme responsible for phosphorylating Ser473 site has not yet been cloned (Hresko, Murata et al. 2003; Murata, Hresko et al. 2003). To date, glucose transporter 4 (GLUT 4) translocation stimulated by Akt/PKB from intracellular compartments to the cell surface membrane in response to insulin in skeletal muscle and adipose tissue is not fully understood.

\subsection{T1DM: to be or not to be insulin resistant, that is the question}

As described previously, T1DM is characterized by hyperglycaemia, i.e., glucose toxicity, which leads to insulin resistance in T1DM patients (Patti, Maffettone et al. 1999). Since T1DM severity is correlated with the degradation of pancreatic $\beta$-cell, most T1DM patients are believed to have varying degree of insulin resistance. A series of studies have demonstrated $30-50 \%$ decreases in rates of insulin-stimulated glucose transport in T1DM patients (DeFronzo 1982; DeFronzo, Hendler et al. 1982; Yki-Jarvinen, Kiviluoto et al. 1986; Vuorinen-Markkola, Koivisto et al. 1992; Chillaron, Goday et al. 2009). One of potential trigger for disturbance of glucose uptake in T1DM results from elevated intramyocellular fat in human skeletal muscle (Krssak, Falk Petersen et al. 1999). In addition, it is well established that T1DM incidence may be related to overweight and obesity especially in children (Baum, Ounsted et al. 1975). More recently, several studies have demonstrated that obesity in childhood was highly related to the risk of subsequent T1DM (Kordonouri and Hartmann 2005; Ljungkrantz, Ludvigsson et al. 2008; Lammi, Moltchanova et al. 2009). Two factors are principally known to be the main components of the relationship between obesity and diabetes: insulin resistance and insulin deficiency (Felber and Golay 2002). These two factors are closely associated in a dual regulatory cycle in which high blood glucose levels promote insulin production which, in turn, reduces the increase in glycemia (Ferrannini and Camastra 1998). The effect of glucose is elicited by generating, stimulating, and amplifying signals in the $\beta$-cells (Henquin 2000). Chronic high levels of blood glucose create a glucotoxic milieu, impairing insulin sensitivity. Hence, genetic basis in the development of diabetes for people suffering from obesity could explain both insulin resistance and insulin deficiency (Gerich 1998). As peripheral insulin resistance increases, the adipose tissue produces more fatty acids, and in turn, impaired liver production of glucose. Thus, pancreatic $\beta$-cells may fail to maintain insulin homeostasis (Hegarty, Furler et al. 2003). Chronic hyperglycemia is an independent cause of insulin resistance with clinical importance in the treatment of T1DM (Vuorinen-Markkola, Koivisto et al. 1992). Obesity induces an elevation of delivery of fatty acids in the blood stream that can promote an accumulation of long chain fatty acyl-CoA (LCFACoA), diacylglycerol, and ceramides. These metabolically active molecules stimulate a serine/threonine kinase cascade leading to phosphorylation of serine/threonine sites on IRS-1 and IRS-2, which in turn decreases the capability of the IRSs to activate PI3 kinase (Dresner, Laurent et al. 1999; Itani, Ruderman et al. 2002). A more recent study indicated that intracellular LCFACoA is associated with an 
increased activation of PKC $\theta$ and a decrease in both IRS-1 tyrosine phosphorylation and IRS-1 associated PI3 kinase activity, which is involved in an increased IRS-1 Ser307 phosphorylation. Insulin signaling cascade is eventually altered, thereby impairing glucose uptake (Dresner, Laurent et al. 1999; Patti, Maffettone et al. 1999; Itani, Ruderman et al. 2002). In addition, a study from Thompson and Cooney (Thompson, Lim-Fraser et al. 2000) indicated that LCFACoAs decreased hexokinase activity in homogenates of human and rat soleus muscle in vitro. Hexokinase is the first enzyme of intracellular glucose metabolism and its suppression by LCFACoA might well account for a decrease in glucose influx into the muscle tissue. Furthermore, defects in Akt phosphorylation may also be associated with decreased glucose uptake in T1DM. A study demonstrated that Akt phosphoryation was significantly impaired in insulin-resistant hypoglycemic Goto-Kakizaki rats and this condition was normalized by a drug treatment, suggesting that Akt is a potential site of insulin resistance in T1DM patients (Krook, Kawano et al. 1997).

\section{The consequences of T1DM on protein metabolism}

T1DM patients exhibit overall changes in tissue protein metabolism. These changes are primarily the result of systemic hypoinsulinemia, changes in circulating hormones, intracellular signals, and catabolic factors also. T1DM-associated milieu disrupts tissue protein homeostasis and induces a net negative protein balance, particularly in skeletal muscle. Patients with T1DM often display profound skeletal muscle atrophy, which results in muscle weakness, fatigue, delayed recovery after illness, and has been linked with increased morbidity and mortality (Gordon, Serino et al.; Tisdale; Menconi, Fareed et al. 2007). Skeletal muscle atrophy associated with T1DM results from the upregulation of numerous catabolic factors, which increase protein degradation and decrease processes of protein synthesis. Therefore, understanding the mechanisms underlying T1DM-mediated skeletal muscle atrophy is important for developing potential strategies to preserve or reverse losses in protein, maintain skeletal muscle function and improve the quality of life of people suffering from T1DM. The protein content of a tissue is the result of protein synthesis and degradation (Nair 1995). Numerous pathological diseases disrupt the balance between protein synthesis and degradation resulting in tissue wasting conditions. Although the specific mechanisms underlying the cause of wasting are not completely understood, these conditions display decreased stimulation of protein synthesis and increased expression of catabolic factors that enhanced catabolic activity. T1DM milieu induces protein wasting where skeletal muscle tissue is rapidly degraded in order to provide amino acid substrates for gluconeogenesis in the liver.

\subsection{Protein metabolism in the absence of insulin}

Whole body protein metabolism is typically measured using an isotopically labeled amino acid tracer such as $\mathrm{L}-\left[1^{13} \mathrm{C}\right]$ or $\left[1^{14} \mathrm{C}\right]$ leucine. Leucine is an essential amino acid whose appearance, disappearance, transamination to its ketoacid ( $\alpha$-ketoisocaproate or KIC), and oxidation can be measured to provide an indication of protein breakdown, synthesis, and metabolism (Charlton and Nair 1998). It has been demonstrated that whole-body leucine kinetics in T1DM patients indicated high levels of protein breakdown and metabolism with insulin deprivation relative to non-diabetic controls (Nair, Ford et al. 1995). These measures of protein breakdown, leucine transamination and oxidation are drastically decreased with insulin treatment indicating a decrease in catabolism and amino acid metabolism. 
Interestingly, measures of whole body protein synthesis according to non-oxidative leucine flux were elevated in insulin-deprived T1DM patients above non-diabetic controls. When these patients were treated with insulin, a decrease in whole-body protein synthesis was observed (Nair, Ford et al. 1995; Charlton and Nair 1998). However, insulin treatment to fasted individuals without an increase in plasma amino acids caused a reduction in plasma amino acids (Charlton and Nair 1998). Several studies showed that when insulin treatment was administered to T1DM patients or healthy controls with an amino acid load increase in whole body protein synthesis occurred (Castellino, Luzi et al. 1987; Tessari, Inchiostro et al. 1987; Luzi, Castellino et al. 1990; Inchiostro, Biolo et al. 1992), although other studies were unable to measure an increase in protein synthesis (Flakoll, Kulaylat et al. 1989; Bennet, Connacher et al. 1991). In order to understand the underlying mechanisms of whole body protein metabolism with insulin treatment, it appears useful to evaluate the relative changes in individual tissues and cellular compartments. The primary responsive tissues to insulinmediated changes in protein metabolism include hepatic, gastrointestinal, cardiac, and skeletal muscle. Numerous studies have measured the rates of protein synthesis and degradation using amino acid tracers (Charlton and Nair 1998). An increase in both protein degradation and protein synthesis has been observed in T1DM patients in the absence of insulin treatment (Charlton and Nair 1998; Herbert and Nair 2010). The rate of protein degradation in the absence of insulin treatment is higher than the rate of protein synthesis resulting in a net loss of whole body protein. T1DM patients in an insulin-deprived state display elevated skeletal muscle proteolysis and splanchnic bed protein synthesis. High rates of protein synthesis measured in the splanchnic bed may be related primarily to hepatic and/or gastrointestinal tissue activity. With insulin treatment, skeletal muscle proteolysis is inhibited while splanchnic bed protein synthesis is decreased. This decrease in splanchnic bed protein synthesis may be mediated by decreases in glucagon and gluconeogenic activity in hepatic tissue in response to insulin treatment (Herbert and Nair 2010). The splanchnic bed has a much higher rate of protein turnover than skeletal muscle which could account for the association between splanchnic bed and whole-body protein metabolism (Charlton and Nair 1998). Therefore, despite the larger total mass of skeletal muscle relative to total splanchnic mass, whole-body protein metabolism is likely to mimic that of the rapid protein turnover splanchnic bed in T1DM patients.

\subsection{Lack of insulin in T1DM induces protein degradation}

Insulin is considered a potent anabolic hormone. Insulin treatment promotes skeletal muscle protein accretion primarily through inhibition of mechanisms of protein degradation (Charlton, Balagopal et al. 1997; Fawcett, Permana et al. 2007). Although studies do not agree whether insulin alone stimulates protein synthesis in vivo, insulin treatment plays an important role in supporting mechanisms of protein synthesis. Evidence supports a necessity for the presence of insulin and amino acids, (leucine in particular) in order to maximally stimulate skeletal muscle protein synthesis with feeding (Anthony, Yoshizawa et al. 2000; Balage, Sinaud et al. 2001; Anthony, Lang et al. 2002; Anthony, Reiter et al. 2002). Insulin receptor binding signals through the PI3K/AKT/mTORC1 pathway and mediates control of the mRNA binding step of translation initiation (Kimball and Jefferson; Anthony, Lang et al. 2002). The mammalian target of rapamycin complex 1 (mTORC1) is a prominent signaling protein where multiple positive and negative signals converge to influence the phosphorylation of downstream regulators of translation initiation, p70 S6K1 and eIF4E- 
binding protein 4E-BP1 (Kimball and Jefferson). mTORC1 mediates phosphorylation and activation of protein kinase S6K1 which activates translation initiation and elongation factors leading to the activation of mRNA cap binding and mRNA joining to the $43 \mathrm{~S}$ preinitiation complex of the ribosome (Fenton and Gout; Kimball and Jefferson). In addition, mTORC1 mediated phosphorylation of 4E-BP1 decreases its affinity for binding translation initiation factor eIF4E, allowing it to interact with eIF4G in formation of the active mRNA cap-binding complex, eIF4F (Kimball and Jefferson; Anthony, Lang et al. 2002). Modulation of these two regulatory steps in translation initiation account for much of the increase in skeletal muscle protein synthesis with feeding in healthy non-diabetics (Kimball and Jefferson). Numerous animal studies have used chemical (streptozotocin, alloxan, diazoxide, and somatostatin) or procedures (pancreatecomy) to induce T1DM by abrogating the release of insulin from pancreatic $\beta$-cells. These agents allow for the study of insulin's influence on many physiological processes including protein metabolism. Using STZ-treated rats, we demonstrated a decrease in skeletal muscle mass (Kelleher). Skeletal muscle and liver protein synthesis are stimulated with increases in plasma amino acids and insulin (Yoshizawa, Kimball et al. 1998). The amino acid, leucine, is unique in its ability to stimulate skeletal muscle protein synthesis through the mTORC1 pathway (Anthony, Yoshizawa et al. 2000). Carbohydrate feeding without the supplementation of amino acids increases serum insulin, but does not increase skeletal muscle protein synthesis (Anthony, Anthony et al. 2000). Taken together, both amino acids (leucine) and insulin are required to stimulate muscle protein synthesis with feeding. In T1DM animal models, basal skeletal muscle protein synthesis is decreased relative to non-alloxan-treated controls, but increases proportionally with leucine gavage (Anthony, Reiter et al. 2002). Phosphorylation of 4E-BP1 and S6K1 were either attenuated or unresponsive to leucine or meal feeding in the absence of insulin, but responded to leucine gavage in a dose-dependent manner to insulin treatment (Gordon, Serino et al.; Balage, Sinaud et al. 2001; Anthony, Lang et al. 2002; Anthony, Reiter et al. 2002). When insulin-unresponsive neonatal pigs were treated with leucine, increases in skeletal muscle protein synthesis were associated with increased eIF4E availability for eIF4F formation (Escobar, Frank et al. 2005). Therefore, feeding-induced skeletal muscle protein synthesis appeared to be both insulin-dependent (phosphorylation of 4E-BP1 and S6K1) and insulin-independent (eIF4E availability) mechanisms (Anthony, Reiter et al. 2002). Thus, decreases in the rate of skeletal muscle protein synthesis in T1DM can be attributed to multiple factors. Hypoinsulinemia has been shown to decrease feedinginduced protein synthesis due to resistance to leucine stimulation of the translational regulators 4E-BP1 and S6K1 (Gordon, Serino et al.). Furthermore, the lack of circulating insulin reduces $\mathrm{PI} 3 \mathrm{~K} / \mathrm{AKT} / \mathrm{mTORC1}$ pathway activation, a pathway which activates a multitude of anabolic signals and inhibits catabolic factors when stimulated (Price, Bailey et al. 1996). In T1DM the inflammatory and hormonal milieu increase protein degradation and decrease synthesis.

\subsection{O-GIcNAcylation of proteins}

Interestingly, hyperglycemia induced by the lack of insulin in T1DM is also capable of interfering with mechanisms of protein synthesis. Glucose can be converted to uridine diphosphate N-acetylglucosamine (UDP-GlcNAc) through the cellular energy sensor hexosamine biosynthetic pathway (Love and Hanover 2005). Hyperglycemia with less wellcontrolled diabetes can increase the amount of O-linked $\beta$--N-acetylglucosamine (O- 
GlcNAc) (Park, Saudek et al.). Increased site-specific O-GlcNAcylation of proteins can be detrimental to protein function thus potentially contributing to the deleterious effects of hyperglycemia seen in T1DM on liver, $\beta$-cell, pancreatic, and red blood cell function (Issad, Masson et al.; Park, Saudek et al.). O-GlcNAcylation of proteins is involved with transcription, translation, ubiquitination, cell cycle, stress responses, and similar to phosphorylation can alter protein posttranslational function and cycle proteins on and off (Butkinaree, Park et al.; Love and Hanover 2005). In T1DM, there is a loss of regulation of OGlcNAcylation and a crosstalk with protein phosphorylation can potentially underlying many of the abnormal protein functions and glucotoxicity exhibited by the disease. OGlcNAcylation may compete with phosphorylation at key sites in the insulin signaling pathway (Love and Hanover 2005). High throughput studies have identified OGlcNAcylation sites on translation factors and core ribosomal proteins that form active polysomes (Zeidan, Wang et al.). Thus modification of ribosomal proteins and signaling pathways by O-GlcNAcylation may play a role in T1DM-associated regulation of signal transduction and translation.

\section{Hormonal influences on T1DM protein metabolism}

The lack of circulating insulin resulting from $\beta$-cell destruction disrupts the production and release of other hormones. T1DM patients and animal models display increases in glucagon, glucocorticoids, catecholamines, and growth hormone which may influence changes in tissue specific protein metabolism independent of hypoinsulinemia. These hormones are the most prominent hormones affecting changes in protein metabolism when hypoinsulinemia results in their irregular production and release.

\subsection{Glucagon}

Basal energy expenditure was increased in T1DM following insulin withdrawal when compared to insulin treatment and non-diabetic control subjects (Nair, Halliday et al. 1984; Charlton and Nair 1998; Karakelides, Asmann et al. 2007). Insulin deprivation in T1DM patients displayed elevations in plasma glucagon which correlate with increased energy expenditure (Nair, Halliday et al. 1984). Evidence support that increased circulating glucagon the ability to increase leucine and phenylalanine oxidation, proteolysis, and whole-body oxygen consumption in T1DM (Nair 1987; Nair, Halliday et al. 1987; Charlton and Nair 1998). In addition to stimulating proteolysis, glucagon induced inhibition of muscle protein synthesis by reducing glucogenic plasma amino acids (Charlton, Adey et al. 1996). High circulating glucagon levels are likely to increase oxygen consumption by stimulating the energy-expensive process of gluconeogenesis, and macroautophagy in the liver of T1DM patients (Nair, Halliday et al. 1984; Mortimore, Poso et al. 1989; Chhibber, Soriano et al. 2000; Karakelides, Asmann et al. 2007). Enhanced hepatic glucose production along with increases in splanchnic region protein synthesis could be attributed to the increases in basal energy expenditure measured in insulin-deprived T1DM (Herbert and Nair 2010).

\subsection{Catecholamines}

Animal models of T1DM display increases in norepinephrine and IL-1-mediated epinephrine (Gwosdow, O'Connell et al. 1992; Baviera, Zanon et al. 2008). IL-1, a key mediator of inflammation, fever, and acute phase response plays an important role in the 
incidence of T1DM (Mandrup-Poulsen, Pickersgill et al.). IL-1 has been shown to stimulate catecholamine release and mediate a stimulatory effect on corticosterone release from the adrenal gland through an $\alpha$-adrenergic receptor (Gwosdow, O'Connell et al. 1992). Catecholamines have been shown to inhibit muscle protein degradation via a cyclic adenosine monophosphate (cAMP) signaling cascade (Baviera, Zanon et al. 2007). Guanthidine-induced chemical sympathectomy of STZ-induced diabetes rats indicates that catecholamines inhibit protein degradation through both Ca2+-dependent and ATPdependent pathways (Baviera, Zanon et al. 2008) that could provide prophylaxis in understanding the disruption of proteins homeostasis in T1DM.

\subsection{Glucocorticoids}

Catabolic doses of glucocorticoids have been implicated in a number of muscle wasting diseases including T1DM where increases in corticosterone production have been observed (Bailey, Wang et al. 1999; Menconi, Fareed et al. 2007). Circulating increases in TNF- $\alpha$ and IL-1 can stimulate the pituitary-adrenal axis to increase secretion of corticosterone (Gwosdow, Kumar et al. 1990; Hall-Angeras, Angeras et al. 1990). Insulinopenia, together with increased glucocorticoids have been shown to enhance muscle protein degradation through increased ubiquitin conjugation to proteins, proteolytic activity, and ubiquitin pathway component mRNA transcription (Price, Bailey et al. 1996; Bailey, Wang et al. 1999). Elevated levels of glucocorticoids have also been found to contribute to skeletal muscle atrophy through increased expression of ubiquitin pathway proteins, transcription factors CCAAT/enhancer-binding protein $\beta$ and $\delta$ and Forkhead box $\mathrm{O}$ (Foxo), and nuclear cofactor p300/histone acetyl transferase (Menconi, Fareed et al. 2007). In addition to catabolic factors, glucocorticoids contribute to muscle atrophy through inhibition of anabolic factors, insulin signaling, and stimulation of protein synthesis (Shah, Kimball et al. 2000; Shah, Kimball et al. 2000; Hu, Wang et al. 2009). Glucocorticoids induce insulin and insulin-like growth factor (IGF-1) resistance through inhibition of the phosphoinositide-3-kinase(PI3K)/ protein kinase $\mathrm{B}(\mathrm{AKT})$ pathway. This mechanism is believed to be caused by interference with PI3K-p85 subunit interaction, preventing activation of insulin receptor substrate-1 (IRS-1) and autoinhibition of the ribosomal protein 56 kinase (p70 S6K1) enzyme (Zheng, Ohkawa et al.; Shah, Iniguez-Lluhi et al. 2002; Hu, Wang et al. 2009). Increases in circulating glucocorticoids also contribute to the observed decreases in the rate of protein synthesis. In addition to their effects on protein degradation, glucocorticoids inhibit muscle protein synthesis through insulin, IGF-1, and leucine resistance. Despite no changes in heart, type I fiber, or liver protein synthesis with glucocorticoid administration for days, rates of skeletal type II muscle fiber protein synthesis were inhibited and maintained at a lower rate (Rannels and Jefferson 1980; Odedra, Bates et al. 1983). Inhibition of skeletal muscle protein synthesis is partially protected by increases in insulin administration in STZ-induced diabetic rats, but cannot produce positive accretion rates with increasing doses (Tomas, Murray et al. 1984) and even low doses of corticosterone induce muscle wasting with low doses of insulin administration in STZ-treated rats (Odedra and Millward 1982). Glucocorticoids appear to inhibit muscle protein synthesis through dephosphorylation and inhibition of 4E-BP1 and S6K and enhanced phosphorylation of eIF4E (Shah, Kimball et al. 2000; Shah, Kimball et al. 2000) along with mechanisms of anabolic factor resistance (Rieu, Sornet et al. 2004). 


\subsection{Growth hormone}

Growth hormone inhibits leucine oxidation and stimulates skeletal muscle protein synthesis, but does not appear to affect mechanisms of protein degradation (Horber and Haymond 1990). Basal growth hormone levels in T1DM patients are normal or elevated when compared to non-diabetics controls depending on glycemic control. Interestingly, IGF-1 levels have been shown to be reduced in T1DM patients (de Sa, Nascif et al.). Alterations to the growth hormone-IGF-1 axis have been linked to hepatic resistance caused by reduced receptors expression and circulating growth hormone binding protein (Bereket, Lang et al. 1999). Poor metabolic control in T1DM alters the growth hormone/IGF-1 axis, but administration of insulin or insulin plus IGF-1 maintain the metabolism associated with this axis. T1DM-mediated hyperglycemia has not been shown to interfere with the rest of the hypothalamic-pituitary axis according to $\mathrm{GH}-$, ACTH and cortisol-releasing mechanisms (de Sa, Nascif et al.; Moyer-Mileur, Slater et al. 2008).

\section{Protein degradation, proteolysis, and pro-catabolic potential signals involved in T1DM}

Tissue mass is the product of both anabolic and catabolic processes. In order to evaluate the fluctuation in tissue size, both rates of protein synthesis and protein degradation are important in order to understand the net protein flux. Protein degradation is important to control the rate-limiting and regulatory proteins in signaling pathways, remove mutated or damaged proteins, and to supply amino acids from muscle proteins for protein synthesis and gluconeogenesis (Price and Mitch 1998). There are four intracellular pathways utilized by eukaryotic cells to degrade proteins including the ATP-dependent ubiquitin-proteasome system, calcium-dependent protease, the lysosomal acid-activated protease, and the ATPindependent caspase pathways. T1DM is a pathological disease with considerable increases in protein degradation.

\subsection{ATP and calcium-dependent proteolytic processes}

Virtually all muscle wasting conditions such as T1DM exhibit increases in protein degradation through activation of the ubiquitin-proteasome system (Hu, Lee et al. 2007). Proteins are degraded in this ATP-dependent proteolytic process when conjugated by covalent attachment to an ubiquitin protein. With the aid of ATP hydrolysis, ubiquitin is transferred between several enzymes (E1, E2, and E3) prior to attachment at specific lysine residues on the target protein serving as a marker for proteolytic degradation. This process is repeated until several ubiquitin proteins are attached in a linear chain targeting the protein for degradation in the proteasome 26S. When targeted proteins meet the proteasome, they are unfolded and fed into the proteasome core where combinations of peptide sequence are recognized and hydrolyzed (Price and Mitch 1998). Calciumdependent protein degradation has been shown to depend on the activity of a family of cysteine proteases called calpains (Costelli, Reffo et al. 2005). Calpains typically exist as inactive heterodimers in the cytoplasm. When the intracellular calcium concentration rises, calpains translocate to the plasma membrane where they are activated by phospholipids which induces a conformational change. This structural change removes regulatory constraints from the catalytic domain, and the catalytic subunit is released in an active state. Thus calpains might be involved in T1DM-related muscle wasting through their mechanism of myofibrillar degradation. Calpains attack the sarcomeric proteins of the Z-disk which 
leads to a disruption of the myofibrils and release of protein substrates for degradation by other proteolytic systems (Costelli, Reffo et al. 2005).

\subsection{Ubiquitin-proteasome involvement in T1DM-induced muscle wasting}

Two muscle protein degradation systems that operate independent of both ATP and calcium include the recruitment of caspases and the endosome-lysosome system and may be upregulated in T1DM. ATP-independent processes of protein degradation involve caspases, cysteine proteases commonly activated with the apoptotic response. A reduction in myonuclei associated with increases in apoptosis indicate that apoptosis plays a role in some models of muscle wasting. However, caspase-3 activation also can mediate skeletal muscle atrophy through actomyosin complex cleavage. Evidence suggests that caspase- 3 activation is an initial step in the process of muscle protein degradation which cleaves larger actomyosin complexes into smaller fragments for other systems (ubiquitin-proteasome) to degrade (Du, Wang et al. 2004). The lysosomal acid-activated protease or endosome-lysosome system primarily degrades long-lived proteins using activated acid proteases in non-selective manner (Costelli, Reffo et al. 2005). This system is commonly incorporated in the recycling of substrates with autophagy. Although some of these proteases are abundant, lysomal degradation is not often involved in skeletal muscle wasting. Protein degradation studies on STZ-induced diabetes indicated increases in the ubiquitin-proteasome and calpain pathways that could be responsible for the skeletal muscle wasting observed with uncontrolled T1DM (Kettelhut, Pepato et al. 1994; Pepato, Migliorini et al. 1996). These studies measured the activity of these pathways in addition to the endosome-lysosomal system for 10 days post-STZ injection and observed variable changes in the systems over time. Within the first 3 days, the increase in skeletal muscle proteolysis was associated with activation of the ubiquitin-proteasome and calpain pathways, and increases in ubiquitin and proteasome subunit mRNA. At 5-10 days post-injection, the activity of these pathways decreased below non-diabetic control measures. The endosome-lysosomal system did not appear to be activated throughout the 10 days of diabetes, and caspase activity could not be measured at this point. After 24 hours of diabetes, rates of protein synthesis were reduced and continued to decrease for the remaining 10 days. Therefore, the STZ-treated animal model appears to develop muscle atrophy as a result of increased ubiquitin-proteasome and calpain pathway activation in addition to decreases in the rate of protein synthesis. In agreement with these two STZ-treatment studies above, increases in skeletal muscle protein degradation in patients and other animal models of T1DM is primarily associated with activation of the ubiquitin-proteasome system (Flakoll, Kulaylat et al. 1989; Smith, Wong et al. 1989; Price, Bailey et al. 1996). Uncontrolled STZ-induced diabetes in rats exhibits increases in both proteolytic capacity and activity (Kettelhut, Pepato et al. 1994; Pepato, Migliorini et al. 1996; Price, Bailey et al. 1996; Hu, Lee et al. 2007; Hu, Klein et al. 2008). In STZ-treated rats, the use of lysosomal and calcium-dependent degradation pathways inhibitors was unable to prevent skeletal muscle proteolysis (Price, Bailey et al. 1996). However, inhibition of the proteasome (MG132) or ATP synthesis decreased muscle proteolysis to similar levels compared to vehicle-treated controls. Therefore the ATPdependent ubiquitin-proteasome pathway seems to mediate protein degradation in T1DM (Price, Bailey et al. 1996; Bailey, Wang et al. 1999).

\subsubsection{Atrophy in T1DM}

Additional evidence of the role of the ubiquitin-proteasome pathway in T1DM is the increased transcription of muscle atrophy-related genes in insulinopenic STZ-treated rats 
(Price, Bailey et al. 1996). Muscle specific ubiquitin E3 ligases atrogin-1/MAFbx, muscle RING finger protein 1 (MuRF1), ubiquitin-conjugating enzyme E2 (14 kDa), and the C3, C5, and $\mathrm{C} 9$ proteasome subunits are important 'atrogenes' in the regulation of muscle mass and typically measured as indicators of muscle proteolytic capacity (Zheng, Ohkawa et al.; Wing and Bedard 1996; Bailey, Wang et al. 1999; Menconi, Fareed et al. 2007). Atrogene mRNAs are typically increased with insulin deficiency or resistance in conditions of muscle wasting and decreased or degraded with insulin and IGF-1 signaling (Wing and Bedard 1996; Price and Mitch 1998). Atrogin-1 and MuRF1 mRNA levels are common indicators of myofibrillar degradation because atrogin-1 targets eukaryotic initiation factor 3 subunit 5 that induces expression of muscle specific proteins and hypertrophy, and MuRF1 targets myosin in muscle (Tisdale). These gene products are atrophy-specific ubiquitin ligases transcribed with FOXO3a activation and nuclear translocation. Increases in atrogin-1 and MuRF1 transcription could indicate that the cell in T1DM is preparing for increases in muscle protein-specific proteolysis. In addition, transcription of atrogenes, expression levels of $26 \mathrm{~S}$ proteasome and ubiquitin are measured as indicators of proteolytic capacity. Ubiquitin conjugation to proteins provides a way of analyzing which proteins are marked for proteolytic degradation. Finally, the chymotrypsin-like peptidase activity of homogenized tissue in the presence and absence of epoxomicin, a proteasome-specific inhibitor, provides a measure of ubiquitin-proteasome activity (Hu, Klein et al. 2008). According to such measurements, skeletal muscle tissue taken from uncontrolled T1DM patients and animal models, strongly indicate activation of the ubiquitin-proteasome system as the primary mode of protein degradation in T1DM. Insulin regulates proteolysis through multiple signals, but direct regulates proteolytic activity through a zinc metalloproteinase, insulindegrading enzyme (IDE) (Duckworth, Bennett et al. 1998; de Tullio, Morelli et al. 2008). IDE co-purifies with the proteasome as part of a cytosolic complex (Duckworth, Bennett et al. 1994). If IDE-proteasome interaction is prevented or IDE activity inhibited, insulin's inhibitory effect on proteolytic activity is not observed (Bennett, Hamel et al. 1997; Duckworth, Bennett et al. 1998; Hamel, Bennett et al. 1998). Although insulin is the primary substrate for IDE, atrial natriuretic peptide, glucagon, proinsulin, IGF-1 and IGF-2 can also bind, get degraded by IDE, and have inhibitory effects on the chymotrypsin-like and trypsin-like catalytic activities of the proteasome (Bennett, Hamel et al. 1997). However, not all substrates equally inhibited proteolytic activity. Insulin analogues with various susceptibility to degradation by IDE showed a positive correlation between substrate degradation, proteolytic activity, and IDE-proteasome dissociation (Bennett, Fawcett et al. 2003). The mechanism by which insulin causes intracellular inhibition of proteolytic activity may be through fragments of degraded insulin or conformational changes in the IDEproteasome complex (Bennett, Hamel et al. 1997; Hamel, Bennett et al. 1998; Bennett, Fawcett et al. 2003). Thus, increases in skeletal muscle proteolytic activity in uncontrolled T1DM are likely associated with a lack of IDE-mediated proteasome inhibition.

\subsubsection{Cross-talk between anabolic-catabolic signaling}

Extensive crosstalk between cellular signaling pathways regulates the processes of protein synthesis and degradation. Insulin, IGF-1, and leucine are among anabolic factors which signal through the $\mathrm{PI} 3 \mathrm{~K} / \mathrm{AKT} / \mathrm{mTORC} 1$ pathway, activating regulatory proteins associated with translation initiation and inhibiting mechanisms of protein degradation. Glucocorticoids and circulating proinflammatory cytokines are among catabolic factors 
which signal in opposition to insulin by inhibiting mechanisms of protein synthesis and increasing ubiquitin-proteasome pathway activity and apoptosis (Tisdale; Menconi, Fareed et al. 2007). A benefit of crosstalk between the protein synthetic and degradation pathways is that it can prevent energy expensive futile cycles. However, crosstalk can also create resistance to anabolic signals in conditions of muscle wasting (Rieu, Sornet et al. 2004). A strong reciprocal relationship exists between PI3K/AKT pathway activation and protein degradation in T1DM. Decreases in PTEN, the phosphatase which turns off PI3K signaling by inactivating phosphatidylinositol 3,4,5-triphosphate (PIP3) to phosphatidylinositol 4,5bisphosphate (PIP2), was shown to suppress STZ-induced increases in proteolysis by maintaining PI3K signaling ( $\mathrm{Hu}$, Lee et al. 2007). PI3K/AKT pathway activation can be decreased in T1DM due to hypoinsulinemia in addition to an increase in circulating glucocorticoids. Glucocorticoids have been found to decrease IRS-1-mediated PI3K signaling due to increases in PI3K-glucocortioid receptor interaction ( $\mathrm{Hu}$, Wang et al. 2009). Glucocorticoid receptor stimulation contributes to muscle protein degradation through inhibition of insulin signaling and can activate muscle proteolysis independently of insulin signaling pathways. The lack of PI3K/AKT activation observed in T1DM models is coupled with increases in both ubiquitin-proteasome activity, and ATP-independent proteolysis in the activation of caspase-3 in skeletal and cardiac muscle (Hu, Lee et al. 2007; Hu, Klein et al. 2008). When the PI3K/AKT pathway is not activated, protein degradation pathways are activated through the dephosphorylation and activation of Foxo's (Sandri, Sandri et al. 2004; Baviera, Zanon et al. 2008). FOXO3a, a critical mediator between growth factor IRS1/PI3K/AKT and IRS2/MEK/ERK signaling, induces the expression of ubiquitin, atrogin-1, and MuRF1 (Tisdale; Zheng, Ohkawa et al.; Sandri, Sandri et al. 2004). In addition to atrogenes, FOXO3a is responsible for apoptotic signaling leading to the loss of mitochondrial membrane permeability, degradation of nuclear DNA, cytochrome c release, Bad phosphorylation, downregulation of FLICE-inhibitory protein, and cleaved (active) caspase 1, 3, and 8 (Hou, Chong et al.; Shang, Chong et al.; Skurk, Maatz et al. 2004). Therefore, FOXO3a may represent a promising target for the treatment of T1DM-mediated skeletal muscle atrophy.

\subsection{Inflammation and increases in protein degradation in T1DM}

As discussed previously in this chapter, pro-inflammatory cytokine play a key role in the pathogenesis of T1DM. Increases in plasma cytokines can have detrimental effects on multiple tissues and is associated with skeletal muscle wasting. For example, aged rats with low grade inflammation resulted in an insensitivity to feeding-induced skeletal muscle protein synthesis (Balage, Averous et al.). Furthermore, inflammation is implicated in the increases in muscle protein degradation, reductions in muscle protein synthesis, and reduced intake of amino acids in a number of pathological conditions (Durham, Dillon et al. 2009). Circulating inflammatory cytokines can alter the release of hormones from the pituitary gland including inflammatory-suppressive glucocorticoids, or can have direct signaling effects on target tissues. The changes in protein metabolism associated with T1DM point towards TNF-a, and IL-1 as pro-inflammatory cytokines which play a role in skeletal muscle atrophy. TNF-a and IL-1 are capable of inducing both direct and indirect effects on skeletal muscle metabolism. TNF-a can inhibit skeletal muscle protein synthesis by inhibiting phosphorylation of 4E-BP1 (Tisdale 2005). This cytokine is further implicated as a 
mediator of skeletal muscle atrophy through the activation of NF-kB. NF-kB activation can inhibit synthesis of the muscle-specific differentiation factor MyoD and is posited to be the stimulator of ubiquitin-proteasome activity induced by cytokines, proteolytic-inducing factor (PIF), and reactive oxygen species (Libera and Vescovo 2004; Tisdale 2005; Durham, Dillon et al. 2009). However, it should be noted that these conclusions come from the literature associated with cancer cachexia and not T1DM, and increases in TNF- $\mathrm{a}$ administration or expression do not always show direct catabolic signaling. In septic rats, TNF-a increased myofibrillar breakdown rates with no changes in the rate of muscle protein synthesis (Zamir, Hasselgren et al. 1992). In healthy rats, TNF- $\alpha$ and IL-1a administration display increases in skeletal muscle proteolysis by different mechanisms (Zamir, Hasselgren et al. 1992). In these studies, TNF-a administration only increased muscle proteolysis when the effects of glucocorticoids were not inhibited (Hall-Angeras, Angeras et al. 1990; Zamir, Hasselgren et al. 1992). With glucocorticoid inhibition (adrenalectomy or receptor antagonist), TNF-a did not have any effect on protein turnover. IL-1a, on the other hand increased muscle proteolysis independently of glucocorticoid inhibition (Zamir, Hasselgren et al. 1992; Zamir, Hasselgren et al. 1993). Therefore, it was determined from these studies that TNF- $\alpha$ increased muscle proteolysis by stimulating the adrenal axis to increase release of glucocorticoids, while IL-1a can stimulate glucocorticoid release and signal muscle proteolysis independently of the mechanism of glucocorticoids (Gwosdow, Kumar et al. 1990; Hall-Angeras, Angeras et al. 1990). TNF-a is an important pro-inflammatory cytokine for understanding T1DM-associated skeletal muscle wasting because it can activate also apoptotic signaling pathways. TNF-a is capable of inducing production of a second messenger, sphingosine, which signals skeletal muscle cell apoptosis (Dalla Libera, Sabbadini et al. 2001). The interaction between TNF- $\alpha$ and TNF receptor 1 has been shown to cause rapid degradation of sphingomyelin which generated sphingosine inside the cell (Wiegmann, Schutze et al. 1992). Although this observation is more common to models of heart failure than STZ-treatment, the number of apoptotic nuclei is positively correlated with circulating TNF-a in T1DM, and the ensuing reduction in number of myonuclei may be responsible for skeletal muscle atrophy (Vescovo, Ambrosio et al. 2001). Therefore, wasting of skeletal muscle in T1DM may be linked to increases in pro-inflammatory regulators such as TNF- $\alpha$ and IL-1 which can influence mechanisms of protein degradation and apoptosis.

\section{Conclusion}

The focus of this chapter was on the various cellular signaling-associated with inflammation that could explain either the etiology or pathogenesis of T1DM. Although the exact cause of T1DM is still unknown, we have gained insight into the cellular mechanisms that are involved. T1DM is defined as an autoimmune disease, therefore inflammatory-related signaling cascades are critical to understand to discover new therapeutic treatment. Among the several transcription factors, NF- $\kappa \mathrm{B}$ is of particular interest as it is involved in both the inflammatory and apoptosis process that could explain the degradation of $\beta$-cells. T1DM milieu influences also mechanisms of protein synthesis and protein degradation. A focus was placed on changes in the skeletal muscle due to the important of muscle in glucose metabolism. As treatments improve, more research is needed to help combat the consequences of T1DM on the quality of life. 


\section{References}

Abdi, R., R. N. Smith, et al. (2002). "The role of CC chemokine receptor 5 (CCR5) in islet allograft rejection." Diabetes 51(8): 2489-95.

Alessi, D. R. (2001). "Discovery of PDK1, one of the missing links in insulin signal transduction. Colworth Medal Lecture." Biochem Soc Trans 29(Pt 2): 1-14.

Alessi, D. R., M. Deak, et al. (1997). "3-Phosphoinositide-dependent protein kinase-1 (PDK1): structural and functional homology with the Drosophila DSTPK61 kinase." Curr Biol 7(10): 776-89.

Anthony, J. C., T. G. Anthony, et al. (2000). "Orally administered leucine stimulates protein synthesis in skeletal muscle of postabsorptive rats in association with increased eIF4F formation." J Nutr 130(2): 139-45.

Anthony, J. C., C. H. Lang, et al. (2002). "Contribution of insulin to the translational control of protein synthesis in skeletal muscle by leucine." Am J Physiol Endocrinol Metab 282(5): E1092-101.

Anthony, J. C., A. K. Reiter, et al. (2002). "Orally administered leucine enhances protein synthesis in skeletal muscle of diabetic rats in the absence of increases in 4E-BP1 or S6K1 phosphorylation." Diabetes 51(4): 928-36.

Anthony, J. C., F. Yoshizawa, et al. (2000). "Leucine stimulates translation initiation in skeletal muscle of postabsorptive rats via a rapamycin-sensitive pathway." J Nutr 130(10): 2413-9.

Bach, J. F., A. Bendelac, et al. (2004). "The role of innate immunity in autoimmunity." J Exp Med 200(12): 1527-31.

Bailey, J. L., X. Wang, et al. (1999). "The balance between glucocorticoids and insulin regulates muscle proteolysis via the ubiquitin-proteasome pathway." Miner Electrolyte Metab 25(4-6): 220-3.

Balage, M., J. Averous, et al. "Presence of low-grade inflammation impaired postprandial stimulation of muscle protein synthesis in old rats." J Nutr Biochem 21(4): 325-31.

Balage, M., S. Sinaud, et al. (2001). "Amino acids and insulin are both required to regulate assembly of the eIF4E. eIF4G complex in rat skeletal muscle." Am J Physiol Endocrinol Metab 281(3): E565-74.

Balamurugan, A. N., R. Bottino, et al. (2006). "Prospective and challenges of islet transplantation for the therapy of autoimmune diabetes." Pancreas 32(3): 231-43.

Barbe-Tuana, F. M., D. Klein, et al. (2006). "CD40-CD40 ligand interaction activates proinflammatory pathways in pancreatic islets." Diabetes 55(9): 2437-45.

Baum, J. D., M. Ounsted, et al. (1975). "Letter: Weight gain in infancy and subsequent development of diabetes mellitus in childhood." Lancet 2(7940): 866.

Baviera, A. M., N. M. Zanon, et al. (2007). "Pentoxifylline inhibits Ca2+-dependent and ATP proteasome-dependent proteolysis in skeletal muscle from acutely diabetic rats." Am J Physiol Endocrinol Metab 292(3): E702-8.

Baviera, A. M., N. M. Zanon, et al. (2008). "Chemical sympathectomy further increases muscle protein degradation of acutely diabetic rats." Muscle Nerve 38(2): 1027-35.

Bell, G. I. and K. S. Polonsky (2001). "Diabetes mellitus and genetically programmed defects in beta-cell function." Nature 414(6865): 788-91. 
Bennet, W. M., A. A. Connacher, et al. (1991). "Effects of insulin and amino acids on leg protein turnover in IDDM patients." Diabetes 40(4): 499-508.

Bennett, R. G., J. Fawcett, et al. (2003). "Insulin inhibition of the proteasome is dependent on degradation of insulin by insulin-degrading enzyme." J Endocrinol 177(3): 399-405.

Bennett, R. G., F. G. Hamel, et al. (1997). "Characterization of the insulin inhibition of the peptidolytic activities of the insulin-degrading enzyme-proteasome complex." Diabetes 46(2): 197-203.

Bereket, A., C. H. Lang, et al. (1999). "Alterations in the growth hormone-insulin-like growth factor axis in insulin dependent diabetes mellitus." Horm Metab Res 31(23): $172-81$.

Butkinaree, C., K. Park, et al. "O-linked beta-N-acetylglucosamine (O-GlcNAc): Extensive crosstalk with phosphorylation to regulate signaling and transcription in response to nutrients and stress." Biochim Biophys Acta 1800(2): 96-106.

Cardozo, A. K., F. Ortis, et al. (2005). "Cytokines downregulate the sarcoendoplasmic reticulum pump $\mathrm{Ca} 2+$ ATPase $2 \mathrm{~b}$ and deplete endoplasmic reticulum $\mathrm{Ca} 2+$, leading to induction of endoplasmic reticulum stress in pancreatic beta-cells." Diabetes 54(2): 452-61.

Castellino, P., L. Luzi, et al. (1987). "Effect of insulin and plasma amino acid concentrations on leucine metabolism in man. Role of substrate availability on estimates of whole body protein synthesis." J Clin Invest 80(6): 1784-93.

Charlton, M. and K. S. Nair (1998). "Protein metabolism in insulin-dependent diabetes mellitus." J Nutr 128(2 Suppl): 323S-327S.

Charlton, M. R., D. B. Adey, et al. (1996). "Evidence for a catabolic role of glucagon during an amino acid load." J Clin Invest 98(1): 90-9.

Charlton, M. R., P. Balagopal, et al. (1997). "Skeletal muscle myosin heavy chain synthesis in type 1 diabetes." Diabetes 46(8): 1336-40.

Charlton, M. R. and K. S. Nair (1998). "Role of hyperglucagonemia in catabolism associated with type 1 diabetes: effects on leucine metabolism and the resting metabolic rate." Diabetes 47(11): 1748-56.

Chhibber, V. L., C. Soriano, et al. (2000). "Effects of low-dose and high-dose glucagon on glucose production and gluconeogenesis in humans." Metabolism 49(1): 39-46.

Chillaron, J. J., A. Goday, et al. (2009). "Estimated glucose disposal rate in assessment of the metabolic syndrome and microvascular complications in patients with type 1 diabetes." J Clin Endocrinol Metab 94(9): 3530-4.

Cnop, M., N. Welsh, et al. (2005). "Mechanisms of pancreatic beta-cell death in type 1 and type 2 diabetes: many differences, few similarities." Diabetes 54 Suppl 2: S97-107.

Costelli, P., P. Reffo, et al. (2005). "Ca(2+)-dependent proteolysis in muscle wasting." Int J Biochem Cell Biol 37(10): 2134-46.

Czech, M. P. and S. Corvera (1999). "Signaling mechanisms that regulate glucose transport." J Biol Chem 274(4): 1865-8.

Dalla Libera, L., R. Sabbadini, et al. (2001). "Apoptosis in the skeletal muscle of rats with heart failure is associated with increased serum levels of TNF-alpha and sphingosine." J Mol Cell Cardiol 33(10): 1871-8. 
de Sa, L. B., S. O. Nascif, et al. "Effects of ghrelin, growth hormone-releasing peptide-6, and growth hormone-releasing hormone on growth hormone, adrenocorticotropic hormone, and cortisol release in type 1 diabetes mellitus." Metabolism 59(10): 153642.

de Tullio, M. B., L. Morelli, et al. (2008). "The irreversible binding of amyloid peptide substrates to insulin-degrading enzyme: a biological perspective." Prion 2(2): 51-6.

DeFronzo, R. A. (1982). "Insulin secretion, insulin resistance, and obesity." Int J Obes 6 Suppl 1: 73-82.

DeFronzo, R. A., R. Hendler, et al. (1982). "Insulin resistance is a prominent feature of insulin-dependent diabetes." Diabetes 31(9): 795-801.

Dogusan, Z., M. Garcia, et al. (2008). "Double-stranded RNA induces pancreatic beta-cell apoptosis by activation of the toll-like receptor 3 and interferon regulatory factor 3 pathways." Diabetes 57(5): 1236-45.

Dotta, F., S. Censini, et al. (2007). "Coxsackie B4 virus infection of beta cells and natural killer cell insulitis in recent-onset type 1 diabetic patients." Proc Natl Acad Sci U S A 104(12): 5115-20.

Dresner, A., D. Laurent, et al. (1999). "Effects of free fatty acids on glucose transport and IRS1-associated phosphatidylinositol 3-kinase activity." J Clin Invest 103(2): 253-9.

Du, J., X. Wang, et al. (2004). "Activation of caspase-3 is an initial step triggering accelerated muscle proteolysis in catabolic conditions." J Clin Invest 113(1): 115-23.

Duckworth, W. C., R. G. Bennett, et al. (1994). "A direct inhibitory effect of insulin on a cytosolic proteolytic complex containing insulin-degrading enzyme and multicatalytic proteinase." J Biol Chem 269(40): 24575-80.

Duckworth, W. C., R. G. Bennett, et al. (1998). "Insulin acts intracellularly on proteasomes through insulin-degrading enzyme." Biochem Biophys Res Commun 244(2): 3904.

Durham, W. J., E. L. Dillon, et al. (2009). "Inflammatory burden and amino acid metabolism in cancer cachexia." Curr Opin Clin Nutr Metab Care 12(1): 72-7.

Eizirik, D. L., M. L. Colli, et al. (2009). "The role of inflammation in insulitis and beta-cell loss in type 1 diabetes." Nat Rev Endocrinol 5(4): 219-26.

Eizirik, D. L. and T. Mandrup-Poulsen (2001). "A choice of death--the signal-transduction of immune-mediated beta-cell apoptosis." Diabetologia 44(12): 2115-33.

Eizirik, D. L., F. Moore, et al. (2008). "Use of a systems biology approach to understand pancreatic beta-cell death in Type 1 diabetes." Biochem Soc Trans 36(Pt 3): 321-7.

Eizirik, D. L., S. Sandler, et al. (1993). "Repair of pancreatic beta-cells. A relevant phenomenon in early IDDM?" Diabetes 42(10): 1383-91.

Eldor, R., A. Yeffet, et al. (2006). "Conditional and specific NF-kappaB blockade protects pancreatic beta cells from diabetogenic agents." Proc Natl Acad Sci U S A 103(13): 5072-7.

Escobar, J., J. W. Frank, et al. (2005). "Physiological rise in plasma leucine stimulates muscle protein synthesis in neonatal pigs by enhancing translation initiation factor activation." Am J Physiol Endocrinol Metab 288(5): E914-21.

Farese, R. V. (2001). "Insulin-sensitive phospholipid signaling systems and glucose transport. Update II." Exp Biol Med (Maywood) 226(4): 283-95. 
Fawcett, J., P. A. Permana, et al. (2007). "Regulation of protein degradation by insulindegrading enzyme: analysis by small interfering RNA-mediated gene silencing." Arch Biochem Biophys 468(1): 128-33.

Felber, J. P. and A. Golay (2002). "Pathways from obesity to diabetes." Int J Obes Relat Metab Disord 26 Suppl 2: S39-45.

Fenton, T. R. and I. T. Gout "Functions and regulation of the 70kDa ribosomal S6 kinases." Int J Biochem Cell Biol 43(1): 47-59.

Ferrannini, E. and S. Camastra (1998). "Relationship between impaired glucose tolerance, non-insulin-dependent diabetes mellitus and obesity." Eur J Clin Invest 28 Suppl 2: 3-6; discussion 6-7.

Filippi, C. and M. von Herrath (2005). "How viral infections affect the autoimmune process leading to type 1 diabetes." Cell Immunol 233(2): 125-32.

Flakoll, P. J., M. Kulaylat, et al. (1989). "Amino acids augment insulin's suppression of whole body proteolysis." Am J Physiol 257(6 Pt 1): E839-47.

Gerich, J. E. (1998). "The genetic basis of type 2 diabetes mellitus: impaired insulin secretion versus impaired insulin sensitivity." Endocr Rev 19(4): 491-503.

Gillespie, K. M. (2006). "Type 1 diabetes: pathogenesis and prevention." CMAJ 175(2): 16570.

Goldberg, A., M. Parolini, et al. (2007). "Toll-like receptor 4 suppression leads to islet allograft survival." FASEB J 21(11): 2840-8.

Gordon, C. S., A. S. Serino, et al. "Impaired growth and force production in skeletal muscles of young partially pancreatectomized rats: a model of adolescent type 1 diabetic myopathy?" PLoS One 5(11): e14032.

Gwosdow, A. R., M. S. Kumar, et al. (1990). "Interleukin 1 stimulation of the hypothalamicpituitary-adrenal axis." Am J Physiol 258(1 Pt 1): E65-70.

Gwosdow, A. R., N. A. O'Connell, et al. (1992). "Interleukin-1-induced corticosterone release occurs by an adrenergic mechanism from rat adrenal gland." Am J Physiol 263(3 Pt 1): E461-6.

Hall-Angeras, M., U. Angeras, et al. (1990). "Interaction between corticosterone and tumor necrosis factor stimulated protein breakdown in rat skeletal muscle, similar to sepsis." Surgery 108(2): 460-6.

Hamel, F. G., R. G. Bennett, et al. (1998). "Regulation of multicatalytic enzyme activity by insulin and the insulin-degrading enzyme." Endocrinology 139(10): 4061-6.

Hanifi-Moghaddam, P., S. Kappler, et al. (2006). "Altered chemokine levels in individuals at risk of Type 1 diabetes mellitus." Diabet Med 23(2): 156-63.

Hegarty, B. D., S. M. Furler, et al. (2003). "The role of intramuscular lipid in insulin resistance." Acta Physiol Scand 178(4): 373-83.

Henquin, J. C. (2000). "Triggering and amplifying pathways of regulation of insulin secretion by glucose." Diabetes 49(11): 1751-60.

Herbert, S. L. and K. S. Nair (2010). "Protein and energy metabolism in type 1 diabetes." Clin Nutr 29(1): 13-17.

Horber, F. F. and M. W. Haymond (1990). "Human growth hormone prevents the protein catabolic side effects of prednisone in humans." J Clin Invest 86(1): 265-72. 
Hou, J., Z. Z. Chong, et al. "FOXO3a governs early and late apoptotic endothelial programs during elevated glucose through mitochondrial and caspase signaling." Mol Cell Endocrinol 321(2): 194-206.

Hresko, R. C., H. Murata, et al. (2003). "Phosphoinositide-dependent kinase-2 is a distinct protein kinase enriched in a novel cytoskeletal fraction associated with adipocyte plasma membranes." J Biol Chem 278(24): 21615-22.

$\mathrm{Hu}$, J., J. D. Klein, et al. (2008). "Cardiac muscle protein catabolism in diabetes mellitus: activation of the ubiquitin-proteasome system by insulin deficiency." Endocrinology 149(11): 5384-90.

$\mathrm{Hu}, \mathrm{Z} ., \mathrm{I}$. H. Lee, et al. (2007). "PTEN expression contributes to the regulation of muscle protein degradation in diabetes." Diabetes 56(10): 2449-56.

$\mathrm{Hu}, \mathrm{Z} ., \mathrm{H}$. Wang, et al. (2009). "Endogenous glucocorticoids and impaired insulin signaling are both required to stimulate muscle wasting under pathophysiological conditions in mice." J Clin Invest 119(10): 3059-69.

Igoillo-Esteve, M., E. N. Gurzov, et al. "The transcription factor B-cell lymphoma (BCL)-6 modulates pancreatic \{beta\}-cell inflammatory responses." Endocrinology 152(2): 447-56.

Inchiostro, S., G. Biolo, et al. (1992). "Effects of insulin and amino acid infusion on leucine and phenylalanine kinetics in type 1 diabetes." Am J Physiol 262(2 Pt 1): E203-10.

Issad, T., E. Masson, et al. "O-GlcNAc modification, insulin signaling and diabetic complications." Diabetes Metab 36(6 Pt 1): 423-35.

Itani, S. I., N. B. Ruderman, et al. (2002). "Lipid-induced insulin resistance in human muscle is associated with changes in diacylglycerol, protein kinase $C$, and IkappaB-alpha." Diabetes 51(7): 2005-11.

Karakelides, H., Y. W. Asmann, et al. (2007). "Effect of insulin deprivation on muscle mitochondrial ATP production and gene transcript levels in type 1 diabetic subjects." Diabetes 56(11): 2683-9.

Keslacy, S., O. Tliba, et al. (2007). "Inhibition of tumor necrosis factor-alpha-inducible inflammatory genes by interferon-gamma is associated with altered nuclear factorkappaB transactivation and enhanced histone deacetylase activity." Mol Pharmacol 71(2): 609-18.

Kettelhut, I. C., M. T. Pepato, et al. (1994). "Regulation of different proteolytic pathways in skeletal muscle in fasting and diabetes mellitus." Braz J Med Biol Res 27(4): 98193.

Kim, H. S., M. S. Han, et al. (2007). "Toll-like receptor 2 senses beta-cell death and contributes to the initiation of autoimmune diabetes." Immunity 27(2): 321-33.

Kimball, S. R. and L. S. Jefferson "Control of translation initiation through integration of signals generated by hormones, nutrients, and exercise." J Biol Chem 285(38): 29027-32.

Kordonouri, O. and R. Hartmann (2005). "Higher body weight is associated with earlier onset of Type 1 diabetes in children: confirming the 'Accelerator Hypothesis'." Diabet Med 22(12): 1783-4. 
Krook, A., Y. Kawano, et al. (1997). "Improved glucose tolerance restores insulin-stimulated Akt kinase activity and glucose transport in skeletal muscle from diabetic GotoKakizaki rats." Diabetes 46(12): 2110-4.

Krssak, M., K. Falk Petersen, et al. (1999). "Intramyocellular lipid concentrations are correlated with insulin sensitivity in humans: a 1H NMR spectroscopy study." Diabetologia 42(1): 113-6.

Lammi, N., E. Moltchanova, et al. (2009). "Childhood BMI trajectories and the risk of developing young adult-onset diabetes." Diabetologia 52(3): 408-14.

Larsen, L., M. Tonnesen, et al. (2007). "Inhibition of histone deacetylases prevents cytokineinduced toxicity in beta cells." Diabetologia 50(4): 779-89.

Libera, L. D. and G. Vescovo (2004). "Muscle wastage in chronic heart failure, between apoptosis, catabolism and altered anabolism: a chimaeric view of inflammation?" Curr Opin Clin Nutr Metab Care 7(4): 435-41.

Ljungkrantz, M., J. Ludvigsson, et al. (2008). "Type 1 diabetes: increased height and weight gains in early childhood." Pediatr Diabetes 9(3 Pt 2): 50-6.

Love, D. C. and J. A. Hanover (2005). "The hexosamine signaling pathway: deciphering the "O-GlcNAc code"." Sci STKE 2005(312): re13.

Luzi, L., P. Castellino, et al. (1990). "Leucine metabolism in IDDM. Role of insulin and substrate availability." Diabetes 39(1): 38-48.

Mandrup-Poulsen, T., L. Pickersgill, et al. "Blockade of interleukin 1 in type 1 diabetes mellitus." Nat Rev Endocrinol 6(3): 158-66.

Martin, A. P., S. Rankin, et al. (2008). "Increased expression of CCL2 in insulin-producing cells of transgenic mice promotes mobilization of myeloid cells from the bone marrow, marked insulitis, and diabetes." Diabetes 57(11): 3025-33.

Mathews, C. E., W. L. Suarez-Pinzon, et al. (2005). "Mechanisms underlying resistance of pancreatic islets from ALR/Lt mice to cytokine-induced destruction." J Immunol 175(2): 1248-56.

Mathis, D., L. Vence, et al. (2001). "beta-Cell death during progression to diabetes." Nature 414(6865): 792-8.

Menconi, M., M. Fareed, et al. (2007). "Role of glucocorticoids in the molecular regulation of muscle wasting." Crit Care Med 35(9 Suppl): S602-8.

Mortimore, G. E., A. R. Poso, et al. (1989). "Mechanism and regulation of protein degradation in liver." Diabetes Metab Rev 5(1): 49-70.

Moyer-Mileur, L. J., H. Slater, et al. (2008). "IGF-1 and IGF-binding proteins and bone mass, geometry, and strength: relation to metabolic control in adolescent girls with type 1 diabetes." J Bone Miner Res 23(12): 1884-91.

Murata, H., R. C. Hresko, et al. (2003). "Reconstitution of phosphoinositide 3-kinasedependent insulin signaling in a cell-free system." J Biol Chem 278(24): 21607-14.

Nair, K. S. (1987). "Hyperglucagonemia increases resting metabolic rate in man during insulin deficiency." J Clin Endocrinol Metab 64(5): 896-901.

Nair, K. S. (1995). "Muscle protein turnover: methodological issues and the effect of aging." J Gerontol A Biol Sci Med Sci 50 Spec No: 107-12.

Nair, K. S., G. C. Ford, et al. (1995). "Protein dynamics in whole body and in splanchnic and leg tissues in type I diabetic patients." J Clin Invest 95(6): 2926-37. 
Nair, K. S., D. Halliday, et al. (1984). "Increased energy expenditure in poorly controlled Type 1 (insulin-dependent) diabetic patients." Diabetologia 27(1): 13-6.

Nair, K. S., D. Halliday, et al. (1987). "Hyperglucagonemia during insulin deficiency accelerates protein catabolism." Am J Physiol 253(2 Pt 1): E208-13.

Nanji, S. A. and A. M. Shapiro (2004). "Islet transplantation in patients with diabetes mellitus: choice of immunosuppression." BioDrugs 18(5): 315-28.

Nicoletti, F., I. Conget, et al. (2002). "Serum concentrations of the interferon-gammainducible chemokine IP-10/CXCL10 are augmented in both newly diagnosed Type I diabetes mellitus patients and subjects at risk of developing the disease." Diabetologia 45(8): 1107-10.

Odedra, B. R., P. C. Bates, et al. (1983). "Time course of the effect of catabolic doses of corticosterone on protein turnover in rat skeletal muscle and liver." Biochem J 214(2): 617-27.

Odedra, B. R. and D. J. Millward (1982). "Effect of corticosterone treatment on muscle protein turnover in adrenalectomized rats and diabetic rats maintained on insulin." Biochem J 204(3): 663-72.

Park, K., C. D. Saudek, et al. "Increased expression of beta-N-acetylglucosaminidase in erythrocytes from individuals with pre-diabetes and diabetes." Diabetes 59(7): 1845-50.

Patti, L., A. Maffettone, et al. (1999). "Long-term effects of fish oil on lipoprotein subfractions and low density lipoprotein size in non-insulin-dependent diabetic patients with hypertriglyceridemia." Atherosclerosis 146(2): 361-7.

Pepato, M. T., R. H. Migliorini, et al. (1996). "Role of different proteolytic pathways in degradation of muscle protein from streptozotocin-diabetic rats." Am J Physiol 271(2 Pt 1): E340-7.

Pfleger, C., A. Kaas, et al. (2008). "Relation of circulating concentrations of chemokine receptor CCR5 ligands to C-peptide, proinsulin and $\mathrm{HbA} 1 \mathrm{c}$ and disease progression in type 1 diabetes." Clin Immunol 128(1): 57-65.

Piemonti, L., B. E. Leone, et al. (2002). "Human pancreatic islets produce and secrete MCP1/CCL2: relevance in human islet transplantation." Diabetes 51(1): 55-65.

Price, S. R., J. L. Bailey, et al. (1996). "Muscle wasting in insulinopenic rats results from activation of the ATP-dependent, ubiquitin-proteasome proteolytic pathway by a mechanism including gene transcription." J Clin Invest 98(8): 1703-8.

Price, S. R. and W. E. Mitch (1998). "Mechanisms stimulating protein degradation to cause muscle atrophy." Curr Opin Clin Nutr Metab Care 1(1): 79-83.

Rabinovitch, A. and W. L. Suarez-Pinzon (2003). "Role of cytokines in the pathogenesis of autoimmune diabetes mellitus." Rev Endocr Metab Disord 4(3): 291-9.

Rannels, S. R. and L. S. Jefferson (1980). "Effects of glucocorticoids on muscle protein turnover in perfused rat hemicorpus." Am J Physiol 238(6): E564-72.

Rieu, I., C. Sornet, et al. (2004). "Glucocorticoid excess induces a prolonged leucine resistance on muscle protein synthesis in old rats." Exp Gerontol 39(9): 1315-21.

Sandri, M., C. Sandri, et al. (2004). "Foxo transcription factors induce the atrophy-related ubiquitin ligase atrogin-1 and cause skeletal muscle atrophy." Cell 117(3): 399-412. 
Sarvetnick, N. E. and D. Gu (1992). "Regeneration of pancreatic endocrine cells in interferongamma transgenic mice." Adv Exp Med Biol 321: 85-9; discussion 91-3.

Shah, O. J., J. A. Iniguez-Lluhi, et al. (2002). "The activated glucocorticoid receptor modulates presumptive autoregulation of ribosomal protein S6 protein kinase, p70 S6K." J Biol Chem 277(4): 2525-33.

Shah, O. J., S. R. Kimball, et al. (2000). "Acute attenuation of translation initiation and protein synthesis by glucocorticoids in skeletal muscle." Am J Physiol Endocrinol Metab 278(1): E76-82.

Shah, O. J., S. R. Kimball, et al. (2000). "Glucocorticoids abate p70(S6k) and eIF4E function in L6 skeletal myoblasts." Am J Physiol Endocrinol Metab 279(1): E74-82.

Shang, Y. C., Z. Z. Chong, et al. "Wnt1, FoxO3a, and NF-kappaB oversee microglial integrity and activation during oxidant stress." Cell Signal 22(9): 1317-29.

Shepherd, P. R., B. T. Nave, et al. (1997). "Differential regulation of phosphoinositide 3kinase adapter subunit variants by insulin in human skeletal muscle." J Biol Chem 272(30): 19000-7.

Sherry, N. A., J. A. Kushner, et al. (2006). "Effects of autoimmunity and immune therapy on beta-cell turnover in type 1 diabetes." Diabetes 55(12): 3238-45.

Shimada, A., J. Morimoto, et al. (2001). "Elevated serum IP-10 levels observed in type 1 diabetes." Diabetes Care 24(3): 510-5.

Skurk, C., H. Maatz, et al. (2004). "The Akt-regulated forkhead transcription factor FOXO3a controls endothelial cell viability through modulation of the caspase- 8 inhibitor FLIP." J Biol Chem 279(2): 1513-25.

Smith, O. L., C. Y. Wong, et al. (1989). "Skeletal muscle proteolysis in rats with acute streptozocin-induced diabetes." Diabetes 38(9): 1117-22.

Strandell, E., D. L. Eizirik, et al. (1990). "Reversal of beta-cell suppression in vitro in pancreatic islets isolated from nonobese diabetic mice during the phase preceding insulin-dependent diabetes mellitus." J Clin Invest 85(6): 1944-50.

Sun, X. J., P. Rothenberg, et al. (1991). "Structure of the insulin receptor substrate IRS-1 defines a unique signal transduction protein." Nature 352(6330): 73-7.

Sun, X. J., L. M. Wang, et al. (1995). "Role of IRS-2 in insulin and cytokine signalling." Nature 377(6545): 173-7.

Swift, S. M., H. A. Clayton, et al. (1998). "The potential contribution of rejection to survival of transplanted human islets." Cell Transplant 7(6): 599-606.

Tessari, P., S. Inchiostro, et al. (1987). "Differential effects of hyperinsulinemia and hyperaminoacidemia on leucine-carbon metabolism in vivo. Evidence for distinct mechanisms in regulation of net amino acid deposition." J Clin Invest 79(4): 1062-9.

Thompson, A. L., M. Y. Lim-Fraser, et al. (2000). "Effects of individual fatty acids on glucose uptake and glycogen synthesis in soleus muscle in vitro." Am J Physiol Endocrinol Metab 279(3): E577-84.

Tisdale, M. J. "Reversing cachexia." Cell 142(4): 511-2.

Tisdale, M. J. (2005). "The ubiquitin-proteasome pathway as a therapeutic target for muscle wasting." J Support Oncol 3(3): 209-17. 
Tomas, F. M., A. J. Murray, et al. (1984). "Interactive effects of insulin and corticosterone on myofibrillar protein turnover in rats as determined by $\mathrm{N}$ tau-methylhistidine excretion." Biochem J 220(2): 469-79.

Uno, S., A. Imagawa, et al. (2007). "Macrophages and dendritic cells infiltrating islets with or without beta cells produce tumour necrosis factor-alpha in patients with recentonset type 1 diabetes." Diabetologia 50(3): 596-601.

Vescovo, G., G. B. Ambrosio, et al. (2001). "Apoptosis and changes in contractile protein pattern in the skeletal muscle in heart failure." Acta Physiol Scand 171(3): 305-10.

Vosters, O., C. Beuneu, et al. (2008). "N-acetylcysteine derivative inhibits CD40-dependent proinflammatory properties of human pancreatic duct cells." Pancreas 36(4): 363-8.

Vuorinen-Markkola, H., V. A. Koivisto, et al. (1992). "Mechanisms of hyperglycemiainduced insulin resistance in whole body and skeletal muscle of type I diabetic patients." Diabetes 41(5): 571-80.

Wang, X., S. Jia, et al. (2008). "Identification of a molecular signature in human type 1 diabetes mellitus using serum and functional genomics." J Immunol 180(3): 192937.

Wen, L., R. E. Ley, et al. (2008). "Innate immunity and intestinal microbiota in the development of Type 1 diabetes." Nature 455(7216): 1109-13.

Wiegmann, K., S. Schutze, et al. (1992). "Human 55-kDa receptor for tumor necrosis factor coupled to signal transduction cascades." J Biol Chem 267(25): 17997-8001.

Wing, S. S. and N. Bedard (1996). "Insulin-like growth factor I stimulates degradation of an mRNA transcript encoding the $14 \mathrm{kDa}$ ubiquitin-conjugating enzyme." Biochem J 319 ( Pt 2): 455-61.

Wright, D. E., J. M. Ryals, et al. (2004). "Diabetes-induced expression of activating transcription factor 3 in mouse primary sensory neurons." J Peripher Nerv Syst 9(4): 242-54.

Yki-Jarvinen, H., T. Kiviluoto, et al. (1986). "Insulin resistance is a prominent feature of patients with pancreatogenic diabetes." Metabolism 35(8): 718-27.

Yoshizawa, F., S. R. Kimball, et al. (1998). "Effect of dietary protein on translation initiation in rat skeletal muscle and liver." Am J Physiol 275(5 Pt 1): E814-20.

Zamir, O., P. O. Hasselgren, et al. (1992). "Tumour necrosis factor (TNF) and interleukin-1 (IL-1) induce muscle proteolysis through different mechanisms." Mediators Inflamm 1(4): 247-50.

Zamir, O., P. O. Hasselgren, et al. (1992). "Evidence that tumor necrosis factor participates in the regulation of muscle proteolysis during sepsis." Arch Surg 127(2): 170-4.

Zamir, O., P. O. Hasselgren, et al. (1993). "In vivo administration of interleukin-1 alpha induces muscle proteolysis in normal and adrenalectomized rats." Metabolism 42(2): 204-8.

Zeidan, Q., Z. Wang, et al. "O-GlcNAc cycling enzymes associate with the translational machinery and modify core ribosomal proteins." Mol Biol Cell 21(12): 1922-36.

Zheng, B., S. Ohkawa, et al. "FOXO3a mediates signaling crosstalk that coordinates ubiquitin and atrogin-1/MAFbx expression during glucocorticoid-induced skeletal muscle atrophy." Faseb J 24(8): 2660-9. 
Zierath, J. R. (2002). "Invited review: Exercise training-induced changes in insulin signaling in skeletal muscle." J Appl Physiol 93(2): 773-81.

Zipris, D. (2008). "Innate immunity and its role in type 1 diabetes." Curr Opin Endocrinol Diabetes Obes 15(4): 326-31. 


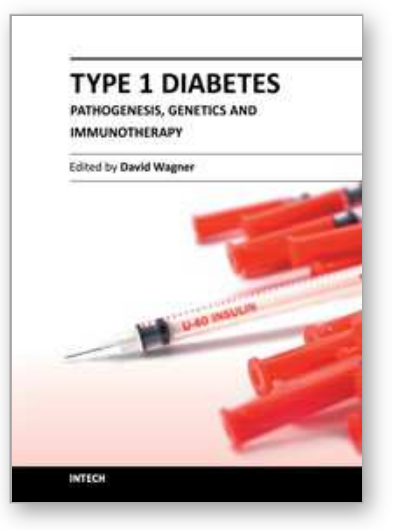

\author{
Type 1 Diabetes - Pathogenesis, Genetics and Immunotherapy \\ Edited by Prof. David Wagner
}

ISBN 978-953-307-362-0

Hard cover, 660 pages

Publisher InTech

Published online 25, November, 2011

Published in print edition November, 2011

This book is a compilation of reviews about the pathogenesis of Type 1 Diabetes. T1D is a classic autoimmune disease. Genetic factors are clearly determinant but cannot explain the rapid, even overwhelming expanse of this disease. Understanding etiology and pathogenesis of this disease is essential. A number of experts in the field have covered a range of topics for consideration that are applicable to researcher and clinician alike. This book provides apt descriptions of cutting edge technologies and applications in the ever going search for treatments and cure for diabetes. Areas including T cell development, innate immune responses, imaging of pancreata, potential viral initiators, etc. are considered.

\title{
How to reference
}

In order to correctly reference this scholarly work, feel free to copy and paste the following:

Lloyd Jesse, Kelleher Andrew, Choi Myung and Keslacy Stefan (2011). Type I Diabetes and the Role of Inflammatory-Related Cellular Signaling, Type 1 Diabetes - Pathogenesis, Genetics and Immunotherapy, Prof. David Wagner (Ed.), ISBN: 978-953-307-362-0, InTech, Available from:

http://www.intechopen.com/books/type-1-diabetes-pathogenesis-genetics-and-immunotherapy/type-i-diabetesand-the-role-of-inflammatory-related-cellular-signaling

\section{INTECH}

open science | open minds

\section{InTech Europe}

University Campus STeP Ri

Slavka Krautzeka 83/A

51000 Rijeka, Croatia

Phone: +385 (51) 770447

Fax: +385 (51) 686166

www.intechopen.com

\section{InTech China}

Unit 405, Office Block, Hotel Equatorial Shanghai

No.65, Yan An Road (West), Shanghai, 200040, China

中国上海市延安西路65号上海国际贵都大饭店办公楼405单元

Phone: $+86-21-62489820$

Fax: +86-21-62489821 
(C) 2011 The Author(s). Licensee IntechOpen. This is an open access article distributed under the terms of the Creative Commons Attribution 3.0 License, which permits unrestricted use, distribution, and reproduction in any medium, provided the original work is properly cited. 